\title{
Rancang Bangun Prototipe Sistem Otomatisasi Pengereman Elektromagnetik Berbasis Mikrokontroler Dengan Kontrol PID
}

Mohammad Hafiz Hersyah ${ }^{1}$, Firdaus ${ }^{2}$, Hamidatul Nesya ${ }^{3}$

${ }^{1,3}$ Sistem Komputer Fakultas Teknologi Informasi Universitas Andalas, Kampus Limau Manis, Padang, 25163, Indonesia

${ }^{2}$ Teknik Elektro Politeknik Negeri Padang, Kampus Limau Manis, Padang, 25163, Indonesia

\section{ARTICLE INFORMATION}

Received: January 18,2018

Revised: March 14, 2018

Available online: March 29. 2018

\section{KEYWORDS}

Kontrol PID, Sensor Ultrasonik, Pengereman Otomatis, elektromagnetik

\section{CORRESPONDENCE}

E-mail: mhafiz@fti.unand.ac.id

\section{A B S T R A C T}

Sistem otomatisasi pengereman diperlukan untuk mempermudah manusia melakukan pekerjaannya dalam pengereman saat berkendara. Tugas Akhir ini bertujuan untuk merancang dan membangun sebuah sistem pengereman elektromagnetik otomatis yang mampu membuat mobil berhenti sebelum menabrak penghalang dengan menerapkan metode kontrol Proportional Integral Derivative (PID). Untuk mengetahui seberapa efektif pemanfaatan kontrol PID dalam melakukan otomatisasi pengereman elektromagnetik maka akan dibandingkan dengan hasil pengereman tanpa menggunakan PID. Penentuan hasil tuning parameter kontroler PID didapatkan dengan menggunakan metode trial and error dan didapatkan nilai parameter PID yang cocok $\mathrm{Kp}=2.98, \mathrm{Ki}=0.104$ dan $\mathrm{Kd}=1.35$. Sensor Ultrasonik digunakan sebagai pendeteksi jarak ke penghalang. Dari hasil pengujian sistem pengereman elektromagnetik dengan kontrol PID lebih efektif digunakan jika dibandingkan dengan sistem pengereman elektromagnetik tanpa PID karena dapat dilihat dari sisi berhentinya mobil mendekati set point, pengereman elektromagnetik dengan kontrol PID lebih bagus hasilnya jika dibandingkan dengan pengereman elektromagnetik tanpa kontrol PID. 


\section{PENDAHULUAN}

Kecelakaan merupakan salah satu faktor penyebab kematian terbesar di dunia. Hal ini biasanya disebabkan karena kelalaian individu dalam mengendarai kendaraan. Tidak sedikit dari pengemudi yang mengantuk atau melamun ketika mengemudi sehingga pengemudi tidak menginjak rem pada saat adanya penghalang didepan kendaraan dan menyebabkan terjadinya kecelakaan.

Untuk mengatasi masalah tersebut dapat memanfaatkan sistem otomatisasi yang sangat diperlukan untuk mempermudah manusia dalam melakukan pekerjaannya. Salah satu penerapan sistem otomatisasi untuk mengurangi tingkat kecelakaan yaitu dengan merancang sebuah sistem pengereman otomatis. Sistem ini akan membuat kendaraan melambat dan kemudian berhenti secara otomatis ketika terdeteksi adanya penghalang

\section{LANDASAN TEORI}

Bab ini membahas tentang teori yang mendasari pembuatan publikasi ini.

\section{Sistem Pengereman}

Sistem pengereman (Brake System) adalah sebuah sistem mekanis yang berfungsi untuk menghalangi suatu gerakan. Jika dilihat dari prinsip kerjanya, sistem pengereman berlawanan dengan sistem kopling. Sistem kopling berfungsi untuk mentransmisikan gerak antara poros penggerak dengan poros yang digerakkan. Secara teori sistem pengereman mengurangi kecepatan suatu benda dengan jalan mengkonversi energi kinetik yang ada padanya ke dalam bentuk lain. Dilihat dari bentuk dan cara kerjanya, ada 4 jenis rem yang dikenal dan diaplikasi di berbagai jenis kendaraan.

1. Cakram yaitu rem ini berbentuk piringan dengan sepatu rem menjepit piringannya.

2. Teromol yaitu ram yang banyak digunakan di kendaraan berat seperti truk atau bus.

3. Mesin yaitu memanfaatkan gesekan mekanikal dan hambatan tekanan silinder untuk memperlambat mobil saat pedal gas dilepas.

4. Elektromagnetik yaitu sistem pengereman yang mengubah energi kinetik menjadi listrik. Caranya dengan memanfaatkan putaran roda untuk memutar dinamo yang menghasilkan listrik.

\section{5}

\section{Rem Elektromagnetik}

Sistem pengereman elektromagnetik merupakan sebuah sistem pengereman yang menggunakan gaya elektromagnetik untuk memperlambat suatu gerakan yang umumnya adalah gerakan poros. Sebuah piringan dengan bahan logam non-ferromagnetik terpasang pada sebuah poros yang berputar. Piringan tersebut diapit oleh sisi stator berupa sistem lilitan (kumparan) elektromagnetik yang dapat membangkitkan medan magnet dari aliran listrik. Saat lilitan diberikan input arus listrik yang telah disearahkan maka lilitan akan menimbulkan arus eddy, sehingga muncul medan magnet disekitar piringan logam. Medan magnet ini akan memiliki arah yang berlawanan dengan medan magnet sebelumnya, sehingga menghambat gerakan putar dari poros tersebut (Alhamdi, 2014).

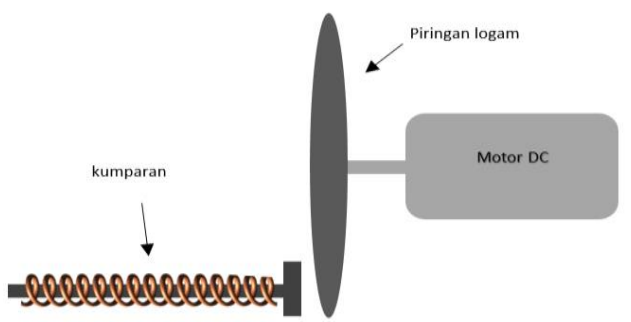

Gambar 1. Rem Elektromagnetis

Solenoid

Solenoid adalah salah satu jenis kumparan terbuat dari kabel panjang yang dililitkan secara rapat dan dapat diasumsikan bahwa panjangnya jauh lebih besar dari pada diameternya. Dalam kasus solenoid ideal, panjang kumparan adalah tak hingga dan dibangun dengan kabel yang saling berhimpit dalam lilitannya, dan medan magnet di dalamnya adalah seragam dan paralel terhadap sumbu solenoid (Halliday, 2001) Solenoid dapat dilihat pada gambar 2.

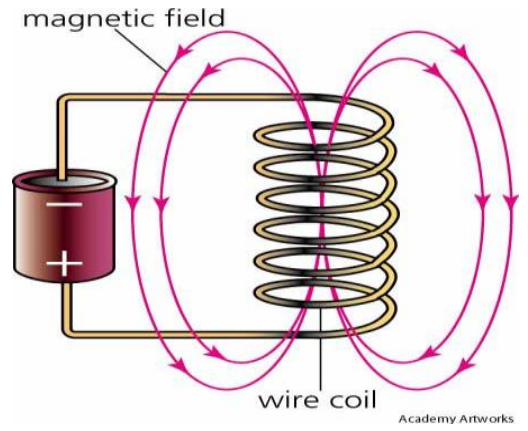

Gambar 2 : Solenoid

\section{Motor DC (Direct Current)}

Motor DC (Direct Current) adalah peralatan elektromagnetik dasar yang berfungsi untuk mengubah tenaga listrik menjadi tenaga mekanik yang desain awalnya diperkenalkan oleh Michael Faraday lebih seabad yang lalu. Motor DC dikendalikan dengan menentukan arah dan kecepatan putarannya. Arah putaran motor DC adalah searah dengan arah putaran jarum jam (Clock Wise/CW) atau berlawanan arah dengan arah putaran jarum jam (Counter Clock Wise/CCW) yang bergantung dari hubungan kutub yang diberikan pada motor DC. Kecepatan putar motor DC diatur dengan besarnya arus yang diberikan (Pitowarnno, 2006). Bagian dasar dari motor DC yaitu:

1. Bagian yang tetap/stasioner yang disebut stator. Stator ini menghasilkan medan magnet, baik yang dibangkitkan dari sebuah koil (elektromagnet) ataupun magnet permanen. 
2. Bagian yang berputar disebut rotor. Rotor ini berupa sebuah koil dimana arus listrik mengalir.

Gambar 3 merupakan gambar motor DC.

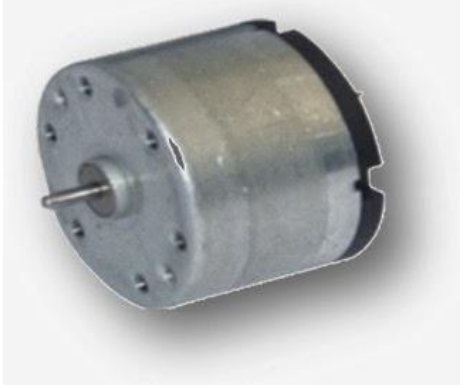

Gambar 3. Motor DC

Untuk dapat melakukan pengaturan kecepatan motor DC dapat menggunakan metode PWM (Pulse Width Modulation). Metode PWM dapat digunakan untuk mengatur kecepatan motor dan untuk menghindarkan rangkaian mengkonsumsi daya berlebih. PWM dapat mengatur kecepatan motor karena tegangan yang diberikan dalam selang waktu tertentu saja. Pada gambar 4 berikut merupakan konfigurasi pin pada IC Driver Motor L298.

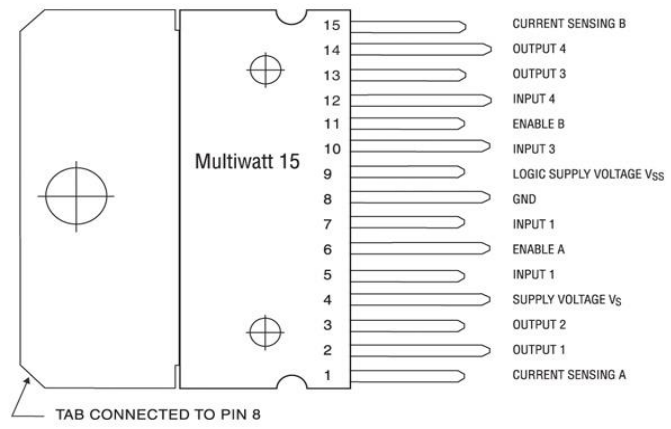

Gambar 4. IC Driver Motor L298

\section{Sensor Ultrasonik}

Sensor ultrasonik adalah sebuah sensor yang mengubah besaran fisis (bunyi) menjadi besaran listrik. Pada sensor ini gelombang ultrasonik dibangkitkan melalui sebuah benda yang disebut piezoelektrik. Sensor ultrasonik secara umum digunakan untuk suatu pengungkapan tak sentuh yang beragam seperti aplikasi pengukuran jarak. Alat ini secara umum memancarkan gelombang suara ultrasonik menuju suatu target yang memantulkan balik gelombang kearah sensor. Kemudian sistem mengukur waktu yang diperlukan untuk pemancaran gelombang sampai kembali ke sensor dan menghitung jarak target dengan menggunakan kecepatan suara dalam medium (Arief, 2011) sebagai berikut:

Bagian-bagian dari sensor ultrasonik adalah

\section{a. Piezoelektrik}

Peralatan piezoelektrik secara langsung mengubah energi listrik menjadi energi mekanik. Tegangan input yang digunakan menyebabkan bagian keramik merengang dan memancarkan gelombang ultrasonik. Tipe operasi transmisi elemen piezoelektrik sekitar frekuensi $32 \mathrm{kHz}$. b. Transmitter

Transmitter adalah sebuah alat yang berfungsi sebagai pemancar gelombang ultrasonik dengan frekuensi sebesar $40 \mathrm{kHz}$ yang dibangkitkan dari sebuah osilator.

c. Receiver

Receiver terdiri dari transduser ultrasonik menggunakan bahan piezoelektrik, yang berfungsi sebagai penerima gelombang pantulan yang berasal dari transmitter yang dikenakan pada permukaan suatu benda atau gelombang langsung LOS (Line of Sight) dari transmitter.

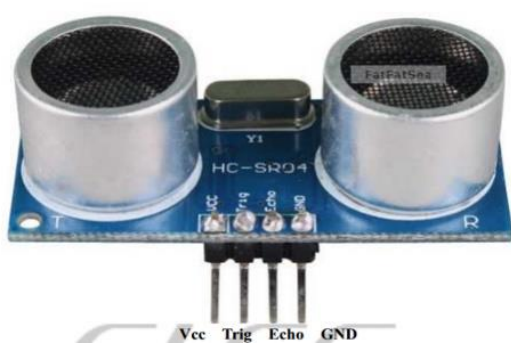

Gambar 5. Sensor Ultrasonik

Mikrokontroller Arduino Uno

Arduino Uno adalah board berbasis mikrokontroler pada ATMega328. Arduino adalah sebuah platform dari physical computing yang bersifat open source berbasis fleksibilitas, dengan hardware dan software yang mudah digunakan. Arduino dapat mendeteksi lingkungannya, dengan menerima input dari berbagai sensor dan memberikan output seperti mengontrol cahaya, motor, dan berbagai aktuator lainnya. Arduino berupa kit elektronik atau papan rangkaian elektronik dengan menggunakan Integrate Development Environment (IDE) yang mengimplementasikan bahasa Wiring/ Processing. Komponen utama di dalam board Arduino adalah sebuah mikrokontroler 8 bit dengan merek ATMega yang dibuat oleh perusahaan Atmel Corporation. Berbagai board Arduino menggunakan tipe ATMega yang berbeda-beda tergantung dari spesifikasinya (Djuandi, 2015). Pada gambar 6 berikut adalah diagram blok dari mikrokontroler ATMega 328 yang dipakai pada Arduino Uno.

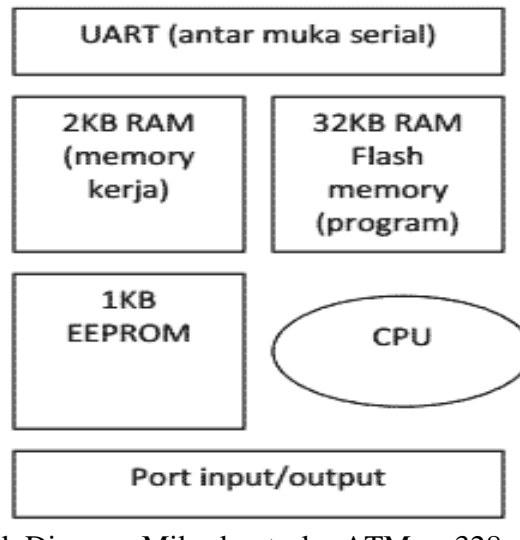

Gambar 6 Blok Diagram Mikrokontroler ATMega328

\section{Software Arduino IDE}

IDE (Integrated Development Environment) adalah sebuah program spesial yang berjalan di komputer yang mengizinkan user menulis sketch untuk board 
Arduino dalam bentuk bahasa pemrograman yang mudah menggunakan Bahasa Processing. Software Arduino ini dapat diinstal di berbagai OS (operating system) seperti: LINUX, Mac OS, Windows. Software Arduino IDE terdiri dari 3 bagian yaitu (Djuandi, 2015):

1. Editor program, untuk menulis dan mengedit program dalam bahasa Processing. Listing program Arduino disebut sketch.

2. Compiler, modul yang berfungsi mengubah bahasa Processing ke dalam kode biner, karena kode biner adalah satu-satunya bahasa program yang dipahami oleh mikrokontroler.

3. Uploader, modul yang berfungsi memasukkan kode biner ke dalam memori mikrokontroler.

Pada gambar 7 berikut adalah tampilan software pada Arduino IDE :

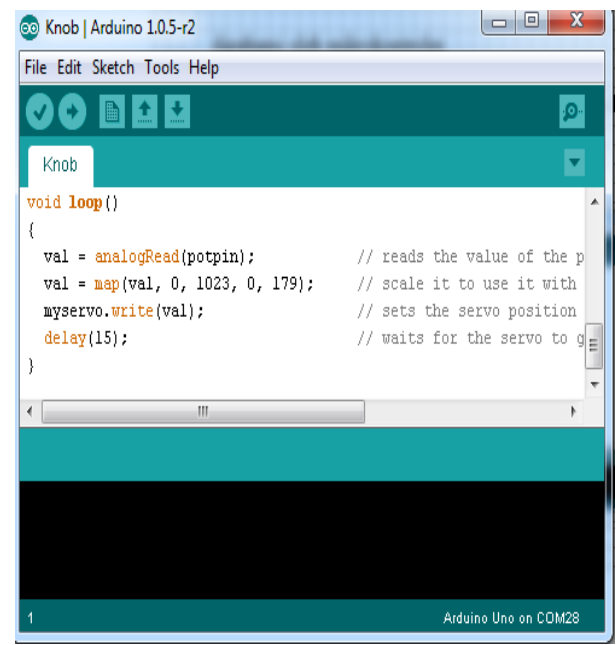

Gambar 7 Arduino IDE

\section{Analog Digital Converter}

Analog Digital Converter (ADC) adalah proses konversi sinyal analog yang didapatkan melalui perangkat analog menjadi sinyal digital yang dibutuhkan dalam pemrosesan di perangkat digital. Proses ADC memiliki tiga tahapan konversi (Widianto, 2012), yaitu pencuplikan (sampling), kuantisasi (quantization) dan pengkodean (coding).

1. Pencuplikan (sampling)

Dalam proses ini, sinyal waktu kontinyu diubah menjadi sinyal waktu diskrit. Parameter proses sampling adalah frekuensi sampling.
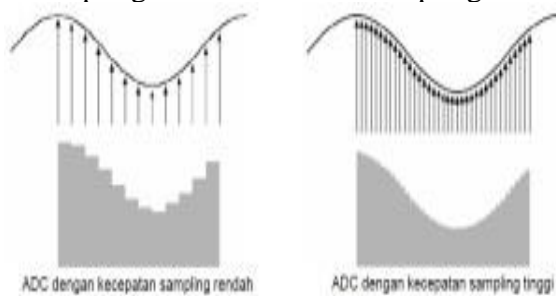

Gambar 8 Ilustrasi Kecepatan Sampling ADC

2. Kuantisasi (Quantization)

Kuantisasi atau Quantization merupakan proses merepresentasikan sebuah sinyal analog yang mempunyai resolusi tak terbatas (kontinyu) ke digital yang mempunyai resolusi terbatas.

3. Pengkodean (coding)
Pengkodean atau coding merupakan proses mentranslasikan analog terkuantisasi menjadi kode digital.

Konversi nilai digital menjadi unit ppm melibatkan resolusi ADC dan tegangan referensi yang digunakan. Suatu sensor memiliki batas minimum ( $\mathrm{min}$ ) dan maksimum ( $\max$ ) nilai deteksi. Dari nilai minimum dan maksimum tersebut, dapat diketahui rentang deteksi sensor. Sehingga dapat dihitung kenaikan tegangan sensor per satu bit.

\section{PWM (Pulse Width Modulation)}

PWM secara umum adalah sebuah cara memanipulasi lebar sinyal yang dinyatakan dengan pulsa dalam suatu perioda, untuk mendapatkan tegangan rata-rata yang berbeda. Atau PWM merupakan cara untuk menyalurkan energi melalui penggantian pulsa dari sebuah sinyal kontinyu (analog). PWM dapat diatur dengan cara memperbesar dan memperkecil lebar pulsa ${ }^{[13]}$.

Beberapa contoh aplikasi PWM adalah pemodulasian data untuk telekomunikasi, pengontrolan daya atau tegangan yang masuk ke beban, regulator tegangan, audio effect dan penguatan, serta aplikasiaplikasi lainnya (Prayogo Rudito. 2012). Pada gambar 9 dapat dilihat sinyal PWM:

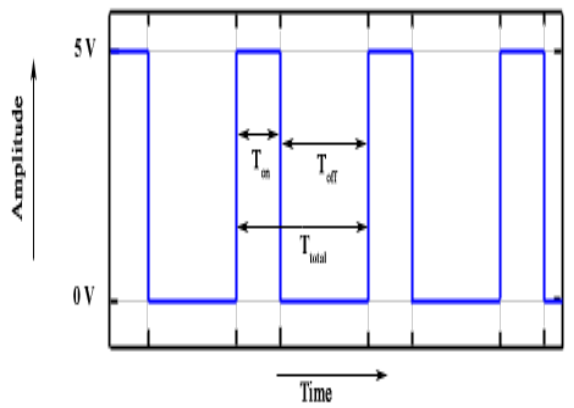

Gambar 9 Sinyal PWM

\section{PID (Proportional Integral Derivative)}

Kontroler PID merupakan kontroler untuk menentukan kepresisian suatu sistem instrumentasi dengan karakteristik adanya umpan balik/feed back pada sistem tersebut (Sukmana, SHT. 2012). Komponen PID terdiri dari 3 jenis, yaitu Proportional, Integratif, dan Derivative. Ketiganya dapat dipakai bersamaan maupun sendiri-sendiri, tergantung dari respon yang kita inginkan terhadap suatu plant.

Masing-masing aksi kontrol ini mempunyai keunggulan-keunggulan tertentu, dimana aksi kontrol proporsional mempunyai keunggulan risetime yang cepat, aksi kontrol integral mempunyai keunggulan untuk memperkecil error, dan aksi kontrol derivative mempunyai keunggulan untuk memperkecil error atau meredam overshot/undershot. Untuk itu agar dapat menghasilkan output dengan risetime yang cepat dan 
error yang kecil kita dapat menggabungkan ketiga aksi kontrol ini menjadi aksi kontrol PID.

Elemen-elemen pengontrol P, I dan D masingmasing secara keseluruhan bertujuan untuk mempercepat reaksi sebuah sistem, menghilangkan offset dan menghasilkan perubahan awal yang besar. Ilustrasi blok diagram PID dapat dilihat pada gambar 10.

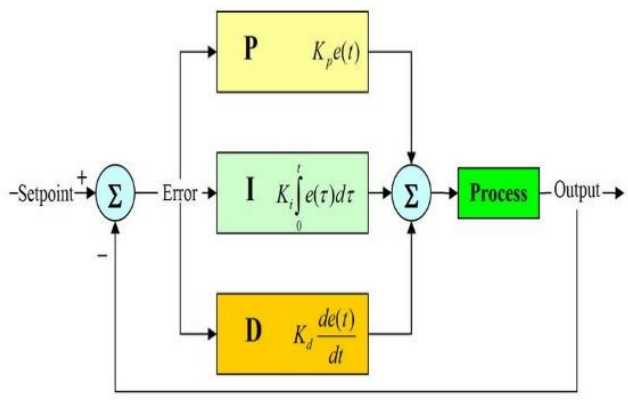

Gambar 10 Blok Diagram PID Controller

\section{METODOLOGI}

Pada penelitian ini akan dilakukan perancangan berupa prototipe sistem otomatisasi pengereman elektromagnetik pada mobil dengan menggunakan kontrol PID. Pada tahap awal, motor DC bergerak untuk menggerakkan roda (piringan logam). Sensor ultrasonik akan mendeteksi adanya penghalang. Setelah didapatkan data jarak penghalang oleh sensor ultrasonik maka data diproses menggunakan kontrol PID pada mikrokontroler selanjutnya akan mengirim sinyal PWM ke solenoid untuk menghasilkan medan magnet dan kemudian menghentikan putaran roda. Berikut adalah rancangan peneilitan pada gambar 10.

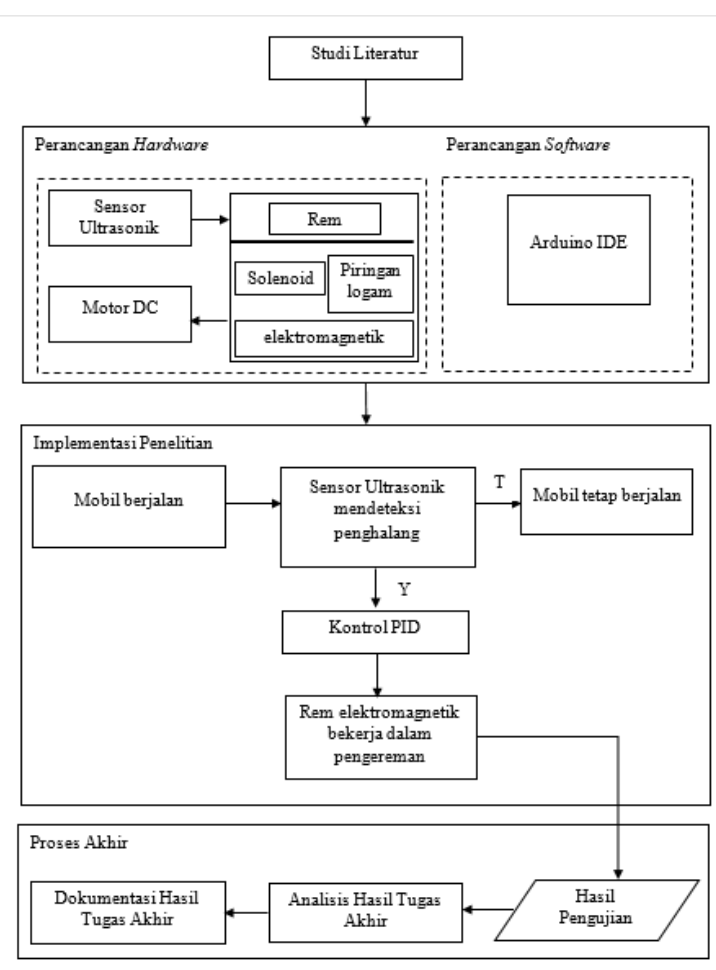

Gambar 10. Rancangan Penelitian

Berdasarkan gambar 10, dapat dijelaskan tahapan-tahapan yang dilakukan untuk menyelesaikan penelitian ini, yaitu sebagai berikut:

1. Studi Literatur

Studi literatur dilakukan dengan mempelajari prinsip kerja sensor ultrasonik HC-SR04 sebagai pendeteksi adanya penghalang, sistem pengereman elektromagnetik sebagai hal utama dalam melakukan pengereman, motor DC sebagai penggerak roda, solenoid sebagai penghasil medan magnet, Arduino Uno sebagai pemroses sistem pengereman otomatis.

2. Perancangan

Perancangan sistem bertujuan untuk memberikan gambaran umum tentang sistem yang akan dibuat. Tahap ini dibagi menjadi dua bagian yaitu perancangan hardware dan software.

a. Perancangan Hardware

Pada perancangan hardware akan dirancang sebuah prototipe mobil dimana roda yang ditempel dengan piringan logam digerakkan oleh motor DC dilengkapi oleh solenoid yang berfungsi untuk memberikan medan magnet kepada piringan logam agar pengereman elektromagnetik dapat bekerja ketika sensor ultrasonik mendeteksi adanya penghalang.

b. Perancangan Software

Perancangan software meliputi pengkodean (coding) pada Arduino IDE.

3. Implementasi penelitian

Pada tahap awal dalam perancangan ini mobil akan berjalan, kemudian sensor ultrasonik akan mendeteksi adanya penghalang, jika penghalang 
terdeteksi maka akan diproses oleh kontrol PID kemudian rem elektromagnetik akan bekerja dalam melakukan pengereman. Dan jika sensor ultrasonik tidak mendeteksi adanya penghalang maka mobil akan tetap berjalan.

4. Proses Akhir

a. Hasil Pengujian

Pada tahap ini dapat dilihat hasil dari sistem yang dibuat. Hasil yang diinginkan dari penelitian ini adalah perancangan berupa prototipe sistem otomatisasi pengereman elektromagnetik pada mobil.

b. Analisis Hasil

Pada tahap ini dilakukan analisa terhadap kinerja sistem dan hal-hal yang mempengaruhi kinerja sistem. Analisa yang dilakukan berdasarkan aspek-aspek yang terdapat pada rumusan masalah. Dalam tahap ini juga dilakukan perbaikan sistem untuk penyempurnaan guna meminimalisir terjadinya kesalahan.

c. Dokumentasi

Tahap ini dilakukan rekap dokumentasi dari hasil yang telah tercapai seperti alat uji, program, dan foto-foto pelaksanaan penelitian.

Berikut adalah blok diagram penelitian yang dijelaskan pada Gambar 11.

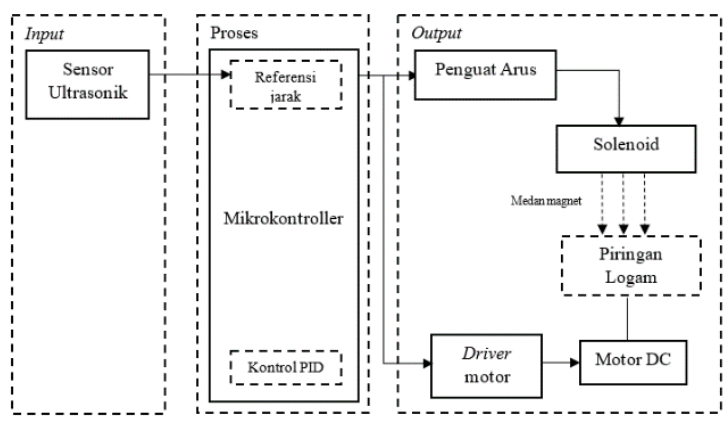

Gambar 11. Blok Diagram

Perancangan sistem pada gambar 11 terdiri dari:

1. Sensor Ultrasonik HC-SR04

Pada perancangan prototipe sistem otomatisasi pengereman elektromagnetik pada mobil ini, sensor ultrasonik HC-SR04 digunakan sebagai pendeteksi jarak penghalang yang berada didepan mobil. Hasil pembacaan sensor ultrasonik diproses pada Mikrokontroler.

2. Mikrokontroler

Pada perancangan sistem ini menggunakan mikrokontroler Arduino Uno yang berperan sebagai pengontrolan pengereman elektromagnetik. Data pembacaan ultrasonik akan diproses dengan kontrol PID dalam mikrokontroler. Setelah diproses diberikan perintah melalui sinyal PWM ke solenoid untuk melakukan pengereman. Pemrograman Arduino sendiri menggunakan Arduino IDE sebagai editor dalam penulisan instruksi program yang akan dibangun.

3. Penguat Arus
Pada perancangan ini penguat arus berfungsi untuk menguatkan arus yang akan dikirimkan kepada solenoid supaya solenoid dapat menghasilkan medan magnet yang kuat.

4. Solenoid

Solenoid pada perancangan ini berfungsi sebagai penghasil medan magnet untuk dapat melakukan pengereman elektromagnetik.

5. Driver Motor

Pada perancangan sistem ini driver motor sebagai pengendali motor DC.

6. Motor DC

Pada perancangan sistem ini motor DC berperan sebagai penggerak mobil (roda) yang akan dihubungan dengan piringan logam untuk pengereman elektromagnetik

7. Piringan logam

Pada perancangan piringan logam berfungsi sebagai komponen utama dalam pengereman elektromagnetik, dimana piringan logam ini akan didekatkan dengan solenoid yang telah diberi arus dan kemudian menghasilkan medan magnet sehingga putaran roda mobil berhenti.

Berikut adalah ilustrasi sistem secara keseluruhan atau program utama pada Gambar 12.

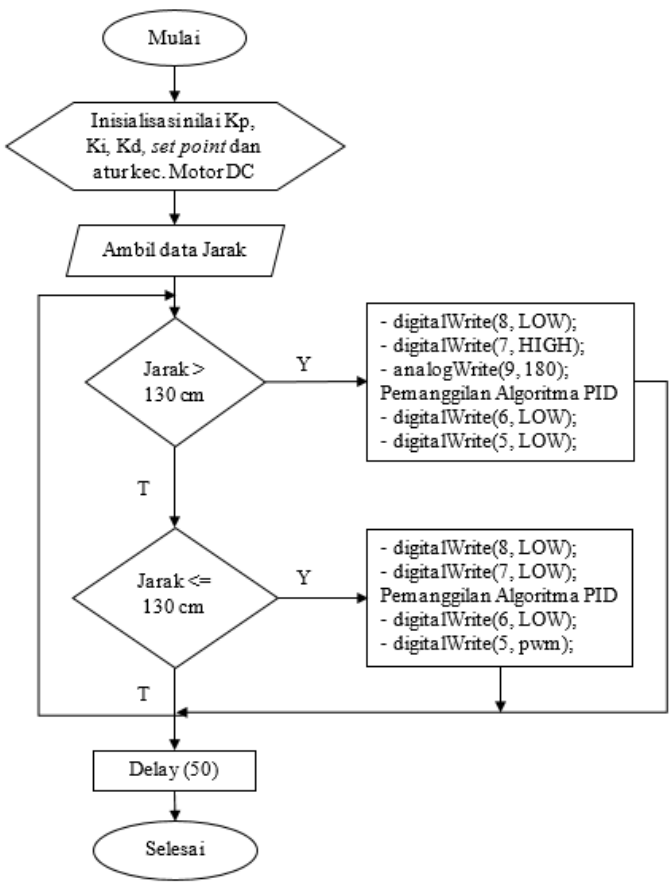

Gambar 12. Diagram Alir Program Utama

\section{HASIL DAN PEMBAHASAN}

Sistem ini dirancang dengan menggunakan motor DC sebagai penggerak roda mobil, driver motor IC L298N sebagai pengatur gerakan motor DC dalam kondisi bergerak atau berhenti, sensor Ultrasonik HC-SR04 sebagai pendeteksi jarak ke penghalang, solenoid sebagai penghasil medan magnet jika dialiri arus listrik yang arusnya dikuatkan oleh penguat arus. Dan piringan logam 
yang melekat pada roda mobil akan ditarik medan magnet yang diberikan solenoid sehingga medan magnet yang dihasilkan solenoid dapat menahan putaran roda pada mobil. Perancangan sistem otomatisasi pengereman elektromagnetik ditampilkan pada gambar 13.

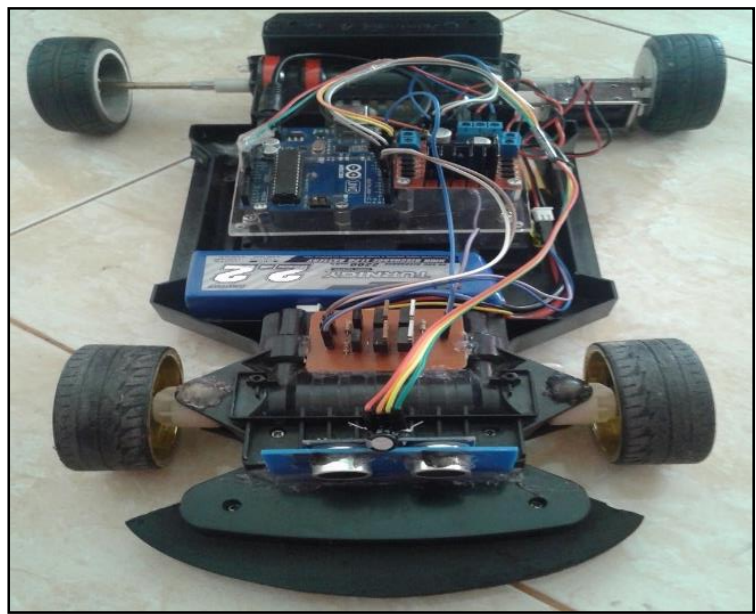

Gambar 13. Implementasi

\section{Pengujian Sensor Ultrasonik HC-SR04}

Pengujian sensor ultrasonik HC-SR04 dilakukan untuk mengetahui jarak sebenarnya menggunakan mistar dengan jarak yang terbaca oleh sensor. Perbandingan tersebut dapat dilihat pada tabel 1 .

Tabel 1 Hasil Pengujian Sensor Ultrasonik HC-SR04

\begin{tabular}{|c|c|c|}
\hline No & $\begin{array}{c}\text { Jarak } \\
\text { Sebenarnya }\end{array}$ & $\begin{array}{c}\text { Jarak terukur oleh } \\
\text { Sensor ultrasonik HC- } \\
\text { SR04 }\end{array}$ \\
\hline 1 & $50 \mathrm{~cm}$ & $50 \mathrm{~cm}$ \\
\hline 2 & $100 \mathrm{~cm}$ & $100 \mathrm{~cm}$ \\
\hline 3 & $130 \mathrm{~cm}$ & $130 \mathrm{~cm}$ \\
\hline 4 & $150 \mathrm{~cm}$ & $149 \mathrm{~cm}$ \\
\hline 5 & $200 \mathrm{~cm}$ & $198 \mathrm{~cm}$ \\
\hline 6 & $250 \mathrm{~cm}$ & $252 \mathrm{~cm}$ \\
\hline 7 & $300 \mathrm{~cm}$ & $298 \mathrm{~cm}$ \\
\hline
\end{tabular}

Berdasarkan Tabel 1 perbandingan jarak yang terbaca oleh sensor ultrasonik HC-SR04 dengan jarak yang sebenarnya terdapat beberapa pembacaan dari sensor yang lebih kecil dan lebih besar dibandingkan dengan jarak sebenarnya dengan selisih $1 \mathrm{~cm}$ dan $2 \mathrm{~cm}$. Pengujian dilakukan pada jarak $50 \mathrm{~cm}-300 \mathrm{~cm}$ dikarenakan sensor ultrasonik pada sistem berfungsi untuk mendeteksi penghalang dan sensor hanya mampu membaca penghalang dengan jarak maksimal $300 \mathrm{~cm}$. Gambar 4.8 adalah hasil pembacaan data oleh sensor ultrasonik HCSR04.

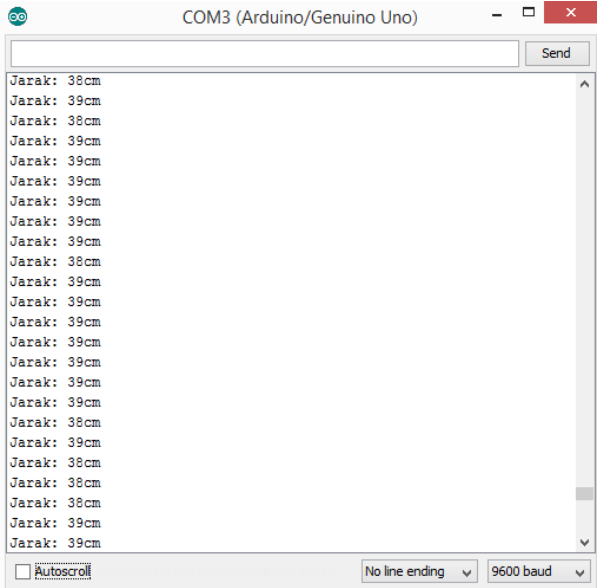

Gambar 14 Deteksi Jarak Yang Terbaca oleh Sensor Ultrasonik HC-SR04

\section{Pengujian Driver Motor}

Driver motor memungkinkan untuk mengendalikan motor DC. Hidup atau tidak hidupnya fungsi dari motor dikontrol melalui pin 7 dan 8 , pin 7 dihubungkan ke pin $\operatorname{In} 2$ dan pin 8 ke pin In1. Sedangkan pengontrolan kecepatan motor didapatkan melalui pengaturan PWM (Pulse Width Modulation) yang terdapat pada pin 9.

Driver Motor ini menggunakan tegangan $5 \mathrm{~V}$ untuk menggunakan kontrol logika dari Arduino. Sedangkan untuk kecepatan motor dapat menggunakan tegangan aman mencapai $12 \mathrm{~V}$ dari Arduino maupun dari power external. Tabel 2 menunjukan rangkaian penguji driver motor.

Tabel 2 Tabel Hasil Pengujian Driver Motor

\begin{tabular}{|c|c|c|}
\hline In1 & In2 & Keadaan Motor \\
\hline LOW & LOW & Motor Mati \\
\hline HIGH & LOW & Motor Mundur \\
\hline LOW & HIGH & Motor Maju \\
\hline
\end{tabular}

Dari tabel 2 dapat dijelaskan bahwa motor akan bergerak sesuai dengan data yang diberikan. Jika data yang diberikan adalah LOW, LOW maka motor tidak bergerak atau mati. Hal ini dikarenakan keluaran dari IC ini akan bernilai 0 (nol) atau tidak ada tegangan yang keluar dari IC tersebut. Jika data yang diberikan adalah HIGH, LOW maka motor akan bergerak mundur. Dan jika data yang diberikan adalah LOW, HIGH maka motor akan bergerak maju. PWM akan bergerak sesuai dengan nilai analogWrite() yang diberikan.

\section{Pengujian Medan Magnet pada Solenoid dengan PWM}

Pengujian medan magnet pada solenoid dengan PWM dilakukan untuk melihat apakah dengan diberikan nilai PWM yang berbeda-beda pada solenoid akan mempengaruhi kekuatan medan magnet pada solenoid. Alat ukur kekuatan medan magnet menggunakan Gauss Meter. Pengujian tersebut dapat dilihat pada Tabel 3. 
Tabel 3 Hasil Pengujian Medan Magnet pada Solenoid dengan PWM

\begin{tabular}{|c|c|c|}
\hline No & $\begin{array}{c}\text { PWM } \\
\text { Solenoid }\end{array}$ & $\begin{array}{c}\text { Kekuatan Medan Magnet } \\
\text { (Gauss) }\end{array}$ \\
\hline 1 & 32 & 7.624 \\
\hline 2 & 64 & 74.408 \\
\hline 3 & 96 & 75.261 \\
\hline 4 & 128 & 75.583 \\
\hline 5 & 160 & 103.743 \\
\hline 6 & 192 & 108.429 \\
\hline 7 & 224 & 131.026 \\
\hline 8 & 255 & 133.137 \\
\hline
\end{tabular}

Berdasarkan Tabel 3 di atas tentang hasil pengujian medan magnet pada solenoid dengan PWM dapat dilihat bahwa dengan nilai PWM yang berbeda diberikan kepada solenoid dapat mempengaruhi kekuatan medan magnet dari solenoid tersebut. Dengan nilai PWM 32 menghasilkan kekuatan medan magnet 7.624 Gauss,

\section{Pengujian Motor DC On /Off}

Pengujian mobil dengan sistem motor DC on/off dilakukan untuk melihat nilai PWM mana yang cocok digunakan dalam melakukan pengereman dengan menggunakan sistem pengereman. Apabila setelah motor dalam keadaan off mobil berhenti atau mobil sudah berhenti sebelum sampai ke penghalang, maka tidak dibutuhkan lagi sistem pengereman. Akan tetapi apabila setelah motor dalam keadaan off mobil tidak berhenti dan melebihi nilai set point bahkan menabrak penghalang, maka dibutuhkan sebuah sistem pengereman.

Pengujian mobil dengan sistem motor DC on/off dilakukan dengan menggunakan 5 kondisi nilai PWM yang berbeda. Hasil pengujian dapat dilihat pada Tabel 4.

Tabel 4 Hasil pengujian Mobil dengan sistem Motor DC on/off

\begin{tabular}{|c|c|c|}
\hline No & Nilai PWM motor & $\begin{array}{c}\text { Jarak berhenti di depan } \\
\text { penghalang }\end{array}$ \\
\hline 1 & 100 & $100 \mathrm{~cm}$ \\
\hline 2 & 130 & $61 \mathrm{~cm}$ \\
\hline 3 & 150 & $4 \mathrm{~cm}$ \\
\hline 4 & 180 & Menabrak penghalang \\
\hline 5 & 200 & Menabrak penghalang \\
\hline
\end{tabular}

Dari tabel 4 dapat disimpulkan bahwa pada saat nilai PWM motor 100, mobil akan berhenti pada jarak 100 $\mathrm{cm}$ di depan penghalang. Pada saat nilai PWM 130 mobil akan berhenti pada jarak $61 \mathrm{~cm}$ di depan penghalang. Dan pada saat nilai PWM motor 150, mobil akan berhenti pada jarak $4 \mathrm{~cm}$ di depan penghalang. Akan tetapi pada saat nilai PWM motor yang diberikan 180 dan 200 mobil akan menabrak penghalang dikarenakan mobil yang terlalu cepat melaju. Dengan demikian, dengan memberikan nilai pwm 100, 130 dan 150 pada motor tidak membutuhkan sistem pengereman lagi karena mobil berhenti sebelum menabrak penghalang sedangkan dengan nilai PWM 180 dan 200 karena mobil menabrak penghalang maka dibutuhkanlah sebuah sistem pengereman supaya mobil berhenti sebelum menabrak penghalang. Maka dari itu, akan dilakukan pengujian pengereman elektromagnetik otomatis dengan nilai PWM yang diberikan kepada motor adalah 180 supaya mobil dapat berhenti sebelum adanya penghalang.

\section{Pengujian Pengereman Elektromagnetik tanpa PID}

Pengujian pengereman elektromagnetik otomatis tanpa kontrol PID dilakukan dengan memberikan nilai PWM secara manual terhadap solenoid dengan rentang jarak yang sudah ditentukan. Pengujian dilakukan sebanyak 10 kali dengan melakukan pengkondisian yang sama terhadap mobil. Nilai PWM yang diberikan kepada solenoid ditentukan sendiri dengan jarak antara nilai PWM yang diberikan adalah 32. Nilai PWM yang diberikan dapat dilihat pada tabel 5 .

Tabel 5 Pengereman dengan Pengkondisian nilai PWM Solenoid

\begin{tabular}{|c|c|c|}
\hline No & Jarak $(\mathrm{cm})$ & $\begin{array}{c}\text { Nilai PWM } \\
\text { Solenoid }\end{array}$ \\
\hline 1 & $120-111$ & 32 \\
\hline 2 & $110-101$ & 64 \\
\hline 3 & $100-91$ & 96 \\
\hline 4 & $90-81$ & 128 \\
\hline 5 & $80-71$ & 160 \\
\hline 6 & $70-61$ & 192 \\
\hline 7 & $60-51$ & 224 \\
\hline 8 & $<=50$ & 255 \\
\hline
\end{tabular}

Dapat dilihat pada tabel 4.5 bahwa dalam setiap rentang jarak akan diberikan nilai PWM solenoid yang berbeda-beda. Untuk mempermudah pengamatan dilakukan pengiriman data berupa data jarak menggunakan komunikasi serial ke komputer. Data-data yang dikirimkan tersebut selanjutnya digambarkan ke dalam grafik hubungan jarak terhadap waktu.

Pengujian dilakukan sebanyak 10 kali pengujian dengan hasil pengujian dapat dilihat pada grafik dalam gambar 14 


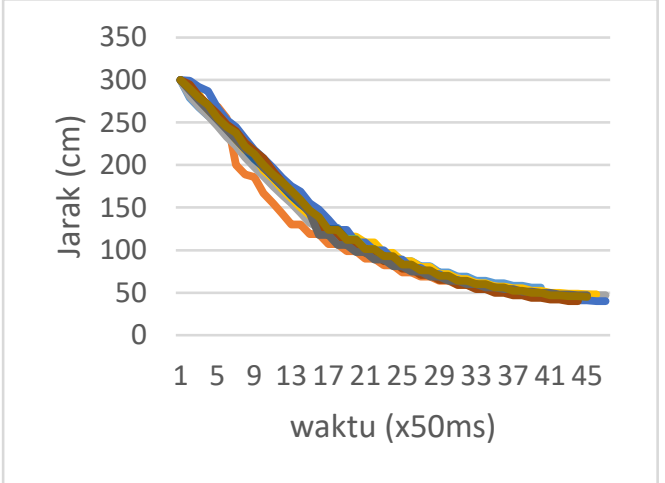

Gambar 14. Grafik Respon Jarak terhadap Waktu

Dapat dilihat pada gambar 4.11 yaitu grafik respon jarak terhadap waktu dalam melakukan pengereman elektromagnetik tanpa kontrol PID. Didapatkan hasil pembacaan jarak oleh sensor yang hampir sama pada setiap percobaan. Pengujian yang telah dilakukan dalam setiap percobaan didapatkan mobil berhenti sebelum menabrak penghalang. Dalam setiap percobaan didapatkan hasil jarak mobil berhenti dari penghalang yaitu dapat dilihat dalam tabel 6 .

Tabel 6 Hasil Pengujian Pengereman Elektromagnetik Otomatis tanpa Kontrol PID

\begin{tabular}{|c|c|c|}
\hline $\begin{array}{c}\text { Percobaan } \\
\text { ke- }\end{array}$ & $\begin{array}{c}\text { Jarak mobil berhenti } \\
\text { di depan penghalang } \\
(\mathrm{cm})\end{array}$ & Keberhasilan \\
\hline 1 & 56 & $\begin{array}{c}\text { Tidak } \\
\text { berhasil }\end{array}$ \\
\hline 2 & 47 & Berhasil \\
\hline 3 & 47 & Berhasil \\
\hline 4 & 48 & Berhasil \\
\hline 5 & 40 & $\begin{array}{c}\text { Tidak } \\
\text { berhasil }\end{array}$ \\
\hline 6 & 41 & $\begin{array}{c}\text { Tidak } \\
\text { berhasil }\end{array}$ \\
\hline 7 & 41 & $\begin{array}{c}\text { Tidak } \\
\text { berhasil }\end{array}$ \\
\hline 8 & 40 & $\begin{array}{c}\text { Tidak } \\
\text { berhasil }\end{array}$ \\
\hline 9 & 47 & Berhasil \\
\hline 10 & 45 & Berhasil \\
\hline
\end{tabular}

Berdasarkan tabel 6 dari 10 kali pengujian yang telah dilakukan, didapatkan tingkat keberhasilan pada pengujian pengereman elektromagnetik tanpa PID yaitu $5 / 10 * 100 \%=50 \%$. Mobil mampu berhenti pada jarak rentang 55-45 $\mathrm{cm}$ di depan penghalang. Karena hasil pencapaian belum maksimal maka digunakan kontrol PID untuk mengatur nilai PWM yang akan diberikan kepada solenoid.

\section{Pengujian Pengereman Elektromagnetik dengan PID}

Pengujian pengereman elektromagnetik otomatis dengan kontrol PID dilakukan dengan menggunakan parameter PID yang berbeda dalam 3 kali pengujian. PID akan menghasilkan nilai PWM yang akan dikirim ke solenoid untuk menghasilkan medan magnet sampai mobil berhenti.
Nilai parameter PID didapatkan dengan metode trial and error sampai didapatkan hasil keluaran yang baik. Dapat dilihat nilai Kp, Ki dan Kd yang manakah yang paling cocok digunakan dalam pengereman otomatis. Nilai Kp, Ki dan Kd yang didapatkan adalah dapat di lihatt pada Tabel 7 :

Tabel 7 Nilai parameter PID pada pengujian

\begin{tabular}{|l|l|l|l|}
\hline & \multicolumn{1}{|c|}{ Kp } & \multicolumn{1}{|c|}{ Ki } & \multicolumn{1}{|c|}{ Kd } \\
\hline Pengujian 1 & 2.198 & 0.8 & 2.6 \\
\hline Pengujian 2 & 2.98 & 0 & 1 \\
\hline Pengujian 3 & 2.98 & 0.104 & 1.35 \\
\hline
\end{tabular}

Untuk mempermudah pengamatan maka dilakukan pengiriman data berupa nilai data jarak dan nilai PWM untuk solenoid yang dihasilkan dari pengendali PID menggunakan komunikasi serial ke komputer. Nilai output PID di batasi sesuai dengan nilai PWM yang diberikan, yaitu antara 0 hingga 255. Data-data yang dikirimkan selanjutnya digambarkan ke dalam grafik hubungan jarak terhadap waktu dan hubungan PWM terhadap waktu. Pada Tabel 8 adalah hasil pengujian pengereman elektromagnetik keseluruhan.

Tabel 8. Pengujian Pengereman Elektromagnetik

\begin{tabular}{|c|c|c|c|c|}
\hline \multirow{2}{*}{ No } & \multirow{2}{*}{ Pengujian } & \multicolumn{2}{|c|}{ Jarak mobil berhenti dari penghalang (cm) } \\
\cline { 3 - 5 } & Percobaan I & Percobaan II & $\begin{array}{c}\text { Percobaan } \\
\text { III }\end{array}$ \\
\hline \multirow{2}{*}{1} & $\begin{array}{c}\mathrm{Kp}=2.198, \\
\mathrm{Ki}=0.8, \mathrm{Kd} \\
=2.6\end{array}$ & 37 & 31 & 39 \\
\hline \multirow{2}{*}{2} & $\begin{array}{c}\mathrm{Kp}=2.98, \\
\mathrm{Ki}=0 \text { dan } \\
\mathrm{Kd}=1\end{array}$ & 46 & 42 & 40 \\
\hline \multirow{2}{*}{3} & $\begin{array}{c}\mathrm{Kp}=2.98, \\
\mathrm{Ki}=0.104 \\
\mathrm{dan} \mathrm{Kd}= \\
1.35\end{array}$ & 47 & 48 & 50 \\
\hline
\end{tabular}

\section{Hasil Pengujian Keseluruhan}

Telah dilakukan pengujian pengereman elektromagnetik otomatis tanpa kontrol PID dan pengujian pengereman elektromanetik dengan kontrol PID. Dari semua pengujian yang telah dilakukan, maka didapatkanlah hasil pengujian. Pengujian dengan sistem motor on/off dilakukan untuk mencari nilai PWM manakah yang cocok digunakan agar sistem pengereman dapat bermanfaat. Hasil perbandingan dari pengujian keduanya dapat dilihat pada Tabel 9.

Tabel 9 Hasil Pengujian Pengereman Elektromagnetik tanpa kontrol PID dan dengan Kontrol PID 


\begin{tabular}{|c|c|c|}
\hline \multirow{2}{*}{ Percobaan ke- } & \multicolumn{2}{|c|}{$\begin{array}{c}\text { Jarak mobil berhenti di depan } \\
\text { penghalang }(\mathrm{cm})\end{array}$} \\
\cline { 2 - 3 } & Tanpa PID & Dengan PID \\
\hline 1 & 56 & 45 \\
\hline 2 & 47 & 48 \\
\hline 3 & 47 & 45 \\
\hline 4 & 48 & 45 \\
\hline 5 & 40 & 45 \\
\hline 6 & 41 & 50 \\
\hline 7 & 41 & 48 \\
\hline 8 & 40 & 47 \\
\hline 9 & 47 & 54 \\
\hline 10 & 45 & 49 \\
\hline
\end{tabular}

Hasil dari data pada tabel 4.10 tersebut, digambarkan kedalam bentuk grafik pada gambar 15 .

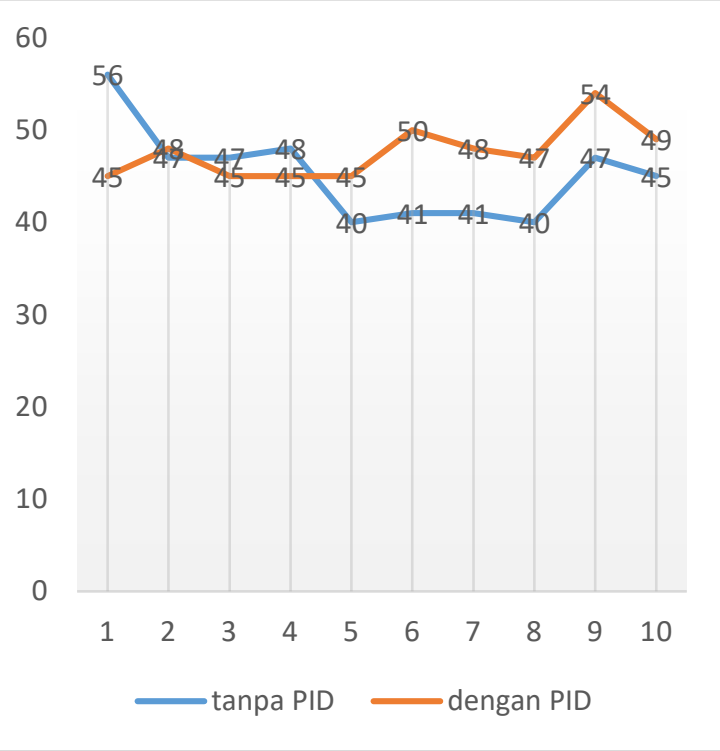

Gambar 15. Grafik Pengujian Pengereman Elektromagnetik tanpa kontrol PID dan dengan Kontrol PID

Perbandingan antara pengereman elektromagnetik tanpa kontrol PID dan dengan kontrol PID setelah dilakukan pengujian, didapatkan hasil bahwa sistem pengereman elektromagnetik dengan kontrol PID lebih efektif digunakan jika dibandingkan dengan sistem pengereman elektromagnetik tanpa PID karena dapat dilihat dari sisi berhentinya mobil mendekati set point dan waktu yang dibutuhkan mobil untuk berhenti mencapai set point pada pengereman elektromagnetik dengan kontrol PID lebih bagus hasilnya jika dibandingkan dengan pengereman elektromagnetik tanpa kontrol PID.

\section{SIMPULAN DAN SARAN}

Berdasarkan perancangan, pengamatan dan pengujian yang telah dilakukan maka dapat diambil kesimpulan sebagai berikut :

1. Dalam sistem pengereman elektromagnetik otomatis pada mobil, mobil mampu berhenti sebelum menabrak penghalang walaupun tidak semua berhenti pada set point.

2. Dari semua pengujian yang telah dilakukan, pengujian yang paling bagus hasilnya yaitu dengan menggunakan parameter PID dengan nilai $\mathrm{Kp}=2.98, \mathrm{Ki}=0.104$ dan $\mathrm{Kd}=1.35$ mobil mampu berhenti mendekati set point pada setiap percobaan.

3. Sistem pengereman elektromagnetik dengan kontrol PID lebih efektif digunakan jika dibandingkan dengan sistem pengereman elektromagnetik tanpa PID karena dapat dilihat dari sisi berhentinya mobil mendekati set point pengereman elektromagnetik dengan kontrol PID lebih bagus hasilnya jika dibandingkan dengan pengereman elektromagnetik tanpa kontrol PID.

4. Dengan mengatur nilai PWM yang diberikan kepada solenoid dapat menghasilkan kuat medan magnet yang bervariasi sehingga dapat memperlambat putaran roda pada mobil.

Mengingat masih banyaknya kelemahan pada penelitian ini, maka perlu dilakukan beberapa perbaikan untuk memperbaiki kinerja alat dan pengembangannya lebih lanjut. Oleh sebab itu, penulis mempertimbangkan beberapa saran yang diperlukan, diantaranya :

1. Mencoba metode kontrol yang lainnya selain PID ataupun menggabungkannya metode kontrol PID.

2. Mencoba sistem pengereman dengan meletakkan solenoid ke kedua roda mobil supaya mobil seimbang.

Pengambilan data dilakukan dengan menggunakan wireless.

\section{DAFTAR PUSTAKA}

[1] Alhamdi, M.Faisal Afif dan Pramudijanto, Josaphat. 2014. Perancangan dan Implementasi Kontroler Knowledge Based - PI pada pengaturan kecepatan motor induksi 3 fasa. Jurnal Teknik Pomits Vol.3, No.1, (2014) ISSN : 2337 - 3539.Arikunto, S. 1998. Prosedur Penelitian. Jakarta: Rinneka Cipta

[2] Halliday; David; Resnick, Robert; Walker, Jearl. 2001. Fundamentals of Physics (ed. 6th). John Wiley \& Sons, Inc. ISBN 9971-51-330-7. England.

[3] Pitowarnno, Endra. 2006. Robotika: Desain, Kontrol, dan kecerdasan Buatan. Andi offset: Yogyakarta.

[4] Arief, U.M. 2011. Pengujian Sensor Ultrasonik PING utuk Pengukuran Level Ketinggian dan Volume Air. Fak. Teknik UNNES, Volume 09/ No.02/Mei

[5] Djuandi, Feri. 2011. Pengenalan Arduino. Diakses dari http://www.tobuku.com/docs/arduino-pengenalan.pdf pada tanggal 05 Oktober 2015.

[6] Prayogo Rudito. 2012. Pengaturan PWM (Pulse Width Modulation) dengan PLC. Universitas Brawijaya. Malang.

[7] Sukmana, SHT. 2012. Perancangan dan Implementasi Kontroler PID untuk Pengendalian Tegangan pada Generator. Fak. Teknik ITS, Vol. 1, (Sept, 2012) ISSN: 2301-927. 